The Digital Object Identifier - DOI: 10.37952/ROI-jbc-01/20-61-1-146

Submitted on January 15, 2020.

\title{
Azo compounds based on 2-(4'-aminophenyl)-4-quinoline carboxylic acid: synthesis and properties
}

\author{
(C) Mirzoolim H. Mavlonov, Dmitry N. Kuznetsov, ${ }^{*+}$ and Konstantin I. Kobrakov \\ Department of Organic Chemistry. A.N. Kosygin Russian State University (Technology. Design. Art). \\ Sadovnicheskaya St., 33, Bild.1. Moscow, 117997.Russia.Phone:+7 (495)811-01-01.E-mail: occd@mail.ru
}

\section{*Supervising author; ${ }^{+}$Corresponding author}

Keywords: 2-(4'-aminophenyl)-4-quinoline carboxylic acid, azo coupling, azo compounds, dyeing, light fastness.

\section{Abstract}

Synthesis and studies of the properties of dyes for coloring textile materials from fibers of various chemical structures, which contain, in addition to chromophore, also pharmacophore groups in the molecule, which impart biocidal properties to both the dyes themselves and the materials dyed by them, are interesting both theoretically and from an applied point of view. The article presents data on the synthesis of a series of previously undescribed azo compounds based on 2-(4'-aminophenyl)-4-quinolinecarboxylic acid and aromatic hydroxy- and aminocompounds of the naphthalene series. Five naphthylazo derivatives of 2-(4'aminophenyl)-4-quinolinecarboxylic acid were synthesized in high yields. The structures of the synthesized azo compounds were confirmed by mass-spectrometry and UV-spectroscopy. In the electronic absorption spectra, the absorption maximum of the synthesized azo compounds lies in the range of 480-550 nm, in contrast to the initial diazo and azo components, the absorption maxima of which lie in the near UV region of the spectrum. Dyeing techniques have been developed that provide optimal indicators for the process of coloration of polypeptide fibers (wool and nylon) with synthesized dyes. The colors of the samples have bright, and deep colors of orange-red-violet scales. The obtained painted samples were examined for color fastness to wet processing according to GOST 9733.4-83, sweat GOST 9733.6-83 and light exposure GOST 11279.2-83. It has been shown that the synthesized azo compounds can be used for coloring woolen and polyamide fibers and provide satisfactory performance properties of dyes, which is consistent with generally accepted ideas about acid dyes. Samples of dyed polyamide fabric showed satisfactory color fastness to light (1-3 points), the best result was shown by wool samples dyed with the studied dyes.

\section{References}

[1] D.B. Patel, R.H. Vekariya, K.D. Patel, N.P. Prajapati, M.S. Vasava, H.D. Patel. Recent advances in synthesis of quinoline-4-carboxylic acid and their biological evaluation: A review. Journal of Chemical and Pharmaceutical Research. 2017. Vol.9. No.2. P.216-230.

[2] J.N. Sangshetti, A.S. Zambare, I. Gonjari, D.B. Shinde. Pfitzinger reaction in the synthesis of bioactive compounds: A review. Mini-Reviews in Organic Chemistry. 2014. Vol.11. No.2. P.225-250. DOI: $10.2174 / 1570193 X 113106660020$

[3] M.G.-A. Shvekhgeimer. The Pfitzinger reaction (review). Chemistry of Heterocyclic Compounds. 2004. Vol.40. No.3. P.257-294. DOI: 10.1023/B:COHC.0000028623.41308.e5

[4] M.-G. A. Shvekhgeimer, N.N. Kondrashova. Synthesis of azo compounds containing the nucleus of 4quinolinecarboxylic acid. Doklady Chemistry. 2003. Vol.391. No.1-3. P.181-184. DOI: 10.1023/A:1024790613111

[5] M.-G.A. Shvekhgeimer, N.N. Kondrashova. Synthesis of novel derivatives of 2-phenylquinoline-4carboxylic acid. Doklady Chemistry. 2002. Vol.383. No.1-3. P.72-74. DOI: 10.1023/A:1014783307934

[6] M.-G.A. Shvekhgeimer, N.N. Kondrashova. Synthesis of new derivatives of 4-quinolinecarboxylic acid. Chemistry of Heterocyclic Compounds. 2002. Vol.38. No.2. P.253-254. DOI: 10.1002/chin.200242163

[7] G.E. Krichevsky, M.V. Korchagin, A.V. Senakhov. Chemical technology of textile materials. Moscow: Legprombytizdat. 1985. 640p. (russian)

[8] GOST 9733.4-83, 9733.6-83. Test methods for color fastness to wet treatments and sweat. Moscow: Publishing House of Standards. 1992. 4p. (russian) 
AZO COMPOUNDS BASED ON 2-(4'-AMINOPHENYL)-4-QUINOLINE CARBOXYLIC ACID: SYNTHESIS... 146-151

[9] GOST 9733.6-83. Test methods for sweat stain resistance. M .: Publishing House of Standards. 1992.4p. (russian)

[10] GOST 11279.2-83. Methods for determining the color fastness to light, light and weather. Moscow: Publishing House of Standards. 1992. 9p. (russian)

[11] N.E. Bulusheva. Basic laboratory workshop on the chemical technology of fibrous materials. Moscow: RIO MSTU. 2000. 330p. (russian) 